202

\section{CONFRONTO TRA DUE SAGGI DI REAL-TIME PCR ED UNA NESTED PCR PER LA DIAGNOSI DI TOXOPLASMOSI}

Calderaro A., Piccolo G., Peruzzi S., Gorrini C., Bommezzadri S., Dettori G., Chezzi C.

Dipartimento di Patologia e Medicina di Laboratorio, Sezione di Microbiologia, Università degli Studi di Parma.

Introduzione. In questo studio sono stati valutati due saggi di Real-time PCR ed un saggio di nested PCR per la diagnosi molecolare di toxoplasmosi da applicare nei casi dove la diagnosi sierologica potrebbe essere di difficile interpretazione. Metodi. Campioni biologici sperimentalmente addizionati di tachizoiti di T.gondii coltivati in cellule VERO e opportunamente diluiti, sono stati utilizzati per valutare la sensibilità di due Real-time PCR ("TaqMan" e "FRET") e di una nested PCR, aventi come bersaglio una regione di 529 pb, ed i geni 18S RNA e B1 di T.gondii, rispettivamente.

La specificità è stata valutata sottoponendo agli stessi saggi DNA di Plasmodium spp., Cryptosporidium spp. e Leishmania infantum.

Sono stati anche saggiati mediante nested-PCR 46 campioni biologici (16 liquidi amniotici, 13 campioni di sangue, 7 liquor, 7 biopsie tissutali e una da linfonodo e 2 campioni di umor vitreo) di donne gravide o pazienti immunodepressi con sospetta infezione da T.gondii.

Risultati. La sensibilità analitica è risultata $10^{3}$ tachizoiti $/ \mathrm{ml}$ (nested e Real-time PCR "TaqMan") e $10^{2}$ tachizoiti/ml ("FRET"). Nessun segnale di PCR è stato osservato saggiando il DNA di Plasmodium spp., Cryptosporidium spp. e Leishmania infantum.

Tre dei 46 campioni esaminati (2 liquor, 1 biopsia cerebrale) sono risultati positivi per la presenza del DNA di T.gondii.

Conclusioni. I saggi di PCR valutati sono sensibili e specifici; in particolare, la FRET-PCR è risultata la più sensibile, probabilmente a causa del maggior numero di copie della sequenza bersaglio presenti nel DNA di T.gondii.

I saggi di Real-time PCR sono di semplice esecuzione e forniscono risultati in tempi più brevi rispetto ai sistemi convenzionali di PCR, riducendo anche il rischio di contaminazione, rendendone così utile l'applicazione in campo diagnostico soprattutto nella nostra realtà in cui nel 2005 la prevalenza dell'infezione da Toxoplasma gondii rilevata su sieri di 3.997 soggetti è stata del $31.57 \%$.

\section{3}

REAL-TIME-PCR PER LA QUANTIZZAZIONE DI CMV-DNA DA SANGUE INTERO NEL FOLLOW-UP DI PAZIENTITRAPIANTATI

Varetto S.; Pittaluga F.; Giliberto G.; Martelli S.; Gabella S.; Allice T.; Ghisetti V.; Marchiaro G.

S.C. Microbiologia, Azienda Ospedaliera S. Giovanni Battista di Torino, c.so Bramante 88/90 - 10126 Torino

Introduzione. Nel trapianto d'organo, il monitoraggio dell'infezione da CMV mediante la ricerca dell'antigene pp65 è il gold-standard per la diagnosi e il trattamento precoce dell'infezione che si associa, in molte realtà di laboratorio, alla determinazione del CMV-DNA che è più precoce. I recenti metodi di Real-Time-PCR offrono una quantizzazione in tempi rapidi e range dinamico più ampio dei tradizionali metodi end-point, ma manca ancora una standardizzazione della matrice biologica di partenza e dell'estrazione del DNA. Lo scopo del lavoro è stato di valutare e confrontare con l'antigenemia un sistema Real-Time-PCR (AmpliMedical, To) per CMV-DNA applicato a sangue intero (200 ul) mediante estrazione completamente automatizzata basata su tecnologia dell'affinità degli acidi nucleici per gel di silice (Qiagen, Mi). Metodi. Sono stati analizzati 388 campioni per CMV-DNA e pp65-antigenemia, provenienti da 128 pazienti (100 con infezione CMV, di cui 28 in trattamento pre-emptive, 72 non trattati, e 28 senza infezione) sottoposti a trapianto d'organo solido e di midollo

Risultati. La correlazione tra Real-Time-PCR e antigenemia è stata buona $(\mathrm{r}=0,648)$. Per valori di antigenemia corrispondenti a 0 , da 1 a 10 , da 11 a 20 , da 21 a 50 , da 51 a 100 e > 100 cellule pp65 positive $/ 200.000$ leucociti, la mediana dei valori di CMV-DNA è stata rispettivamente di 3,3; 3,9; 4,5; 4,6; 5,0 e $5,9 \log _{10} / \mathrm{ml}$. Un plasmide (Clonit, MI.) recante la regione amplificata IE a concentrazione nota è stato usato per testare la sensibilità $(100 \%$ alla concentrazione di 100 copie in amplificazione e $100 \%$ per 5000 copie in estrazione) e la riproducibilità del sistema di estrazione e amplificazione $(\mathrm{CV}$ tra serie $<19 \%$ ). La percentuale di inibizione è stata del $2 \%$. Conclusione. La determinazione di CMV-DNA da sangue intero mediante Real-Time-PCR è risultata altamente riproducibile e sensibile, semplificando e accelerando il processo di quantizzazione di CMV-DNA per scopi clinico-terapeutici.

\section{4}

\section{VALUTAZIONE DEL RISCHIO DI INSORGENZA DI NEFROPATIA ASSOCIATA A POLYOMAVIRUS NELLO SCREENING DITRAPIANTATI RENALI}

Cricca M. ${ }^{1,2}$,Venturoli S.', Ambretti S.', Gentilomi G.', Liviano D'Arcangelo G. ${ }^{3}$, Capelli I. ${ }^{3}$, Scolari M.P. ${ }^{3}$, Musiani M.', Zerbini M.'

'D.M.C.S.S. - Divisione di Microbiologia, Università di Bologna, ${ }^{2}$ C.R.E.M.M. - Azienda Ospedaliera S.Orsola Malpighi; Via Massarenti 9, 40138 Bologna

${ }^{3}$ Unità Operativa di Nefrologia Dialisi e Trapianto

- Azienda Ospedaliera S.Orsola Malpighi; Via Massarenti 9, 40138 Bologna

Introduzione. La nefropatia da polyomavirus (PVAN) è una patologia emergente nei trapiantati renali caratterizzata da malfunzionamento e perdita d'organo nell' $8 \%$ dei casi. L'associazione con la nefropatia è dimostrata per BKV, mentre è ancora da dimostrare per JCV. Attualmente la presenza di una elevata carica di DNA di BKV nelle urine e soprattutto nel plasma di trapiantati di rene è considerata predittiva dell'insorgenza di PVAN.

In questo studio abbiamo messo a punto un saggio di PCR quantitativa per la ricerca di BKV e JCV in urina e plasma di trapiantati renali allo scopo di modulare la terapia antirigetto e ridurre così il rischio di insorgenza di PVAN.

Metodi. È stato allestito un saggio di Real Time PCR per la 